\title{
Produção de carvão ativado de resíduo madeireiro da região Amazônica
}

\section{Activated carbon production of the wood residue of the Amazonian area}

João Rodrigo Coimbra Nobre ${ }^{1}$, Jonnys Paz Castro², Javan Pereira Motta' ${ }^{1}$, Maria Lúcia Bianchi ${ }^{3}$, Paulo Fernando Trugilho ${ }^{4}$, Willian Miguel da Silva Borges ${ }^{5}$ e Jordão Cabral Moulin ${ }^{2}$

\section{Resumo}

Este trabalho objetivou produzir, caracterizar e avaliar o carvão ativado (CA) de resíduos da indústria madeireira da região Amazônica. Resíduos de Apuleia leiocarpa foram coletados, caracterizados quimicamente, transformados em carvão ativado via processo de carbonização $\left(500^{\circ} \mathrm{C}, 1,65^{\circ} \mathrm{C} \cdot \mathrm{min}^{-1}\right.$, por 30 $\mathrm{min})$ e ativados via processo físico $\left(850^{\circ} \mathrm{C}, 10^{\circ} \mathrm{C} \cdot \mathrm{min}^{-1}\right.$, por $\left.60 \mathrm{~min}\right) \mathrm{com} \mathrm{CO}_{2}\left(150 \mathrm{~mL} \cdot \mathrm{min}^{-1}\right)$ e, em seguida, caracterizadas as propriedades adsorventes dos $\mathrm{CA}$ pelo método $\mathrm{BET}$, isotermas e cinéticas de adsorção (azul de metileno e fenol). Verificou-se que o CA apresentou microporosidade elevada, presença de mesoporos e área superficial de $564,90 \mathrm{~m}^{2} \cdot \mathrm{g}^{-1}$, alta capacidade de adsorção em relação às isotermas de azul de metileno (acima de $350 \mathrm{mg}^{-1} \mathrm{~g}^{-1}$ e fenol (acima de $300 \mathrm{mg}^{-1}$ ). Constatou-se que a espécie possui potencial promissor para utilização na produção de carvão ativado de alto valor agregado. Estudos complementares devem ser realizados sobre os parâmetros de carbonização e de ativação a fim de otimizar a produção e qualidade do carvão ativado.

Palavras-chave: madeira de garapa, aproveitamento de resíduos, sustentabilidade ambiental, adsorção.

\begin{abstract}
This research aimed to produce, characterize and evaluate the activated carbon (AC) produced from waste from timber industry of the Amazon region. Waste from Apuleia leiocarpa were collected, characterized chemically, transformed into $\mathrm{AC}$ by carbonization process $\left(500^{\circ} \mathrm{C}, 1.65^{\circ} \mathrm{C} \cdot \mathrm{min}^{-1}\right.$, for $\left.30 \mathrm{~min}\right)$ and activated by physical process $\left(850^{\circ} \mathrm{C}, 10^{\circ} \mathrm{C} \cdot \mathrm{min}^{-1}\right.$ for $\left.60 \mathrm{~min}\right)$, with $\mathrm{CO}_{2}\left(150 \mathrm{~mL} \cdot \mathrm{min}^{-1}\right)$ and then the adsorbent properties of the $\mathrm{AC}$ by the $\mathrm{BET}$ isotherm and kinetics of adsorption (methylene blue and phenol) were characterized. The results demonstrated that the AC has a high microporosity; a certain quantity of mesopores; superficial area of $564.90 \mathrm{~m}^{2} . \mathrm{g}^{-1}$; high adsorption capacity in relation to the isotherms of methylene blue (above 350 $\mathrm{mg} \cdot \mathrm{g}^{-1}$ ) and phenol (above $300 \mathrm{mg}^{-1}$ ). It was concluded that species has quite a promising potential for use in the production of value-added activated carbon. Additional studies should be conducted on the parameters of carbonization and activation in order to optimize the production and quality of activated carbon.
\end{abstract}

Keywords: garapa wood, waste recovery, environmental sustainability, adsorption.

\section{INTRODUÇÃO}

Tendo em vista que produção brasileira de Carvão Ativado (CA) mostra-se insuficiente frente às reais necessidades do país, onde ocorre a necessidade de se importar este produto devido à grande demanda interna, agregar valor aos resíduos madeireiros por meio da produção de CA é uma alternativa viável. Os principais consumidores de CA são as empresas de abastecimento de água potável, empresas de fármacos, transporte de gases, dentre outras, com inúmeras formas de utilização (BORGES et al., 2003). No ano de 2013 as importações chegaram a atingir aproximadamente 23,2 milhões de dólares, sendo 7,5 mil toneladas, mostrando déficit na balança comercial brasileira (MDIC, Aliceweb. 2014).

\footnotetext{
${ }^{1}$ Professor Assistente do Departamento de Tecnologia e Recursos Naturais. UEPA - Universidade do Estado do Pará, Centro de Ciências Naturais e Tecnologia. Travessa Enéas Pinheiro, 2626 - Marco - Belém-PA, PA.- E-mail: rodrigonobre@hotmail.com.br; jpereiramotta@yahoo.com.br.

2Doutorando em Ciência e Tecnologia da Madeira. UFLA - Universidade Federal de Lavras. Departamento de Ciências Florestais - Campus Universitário. Caixa Postal 3037 - 37200-000 - Lavras, MG. E-mail: jonnys 33@ @otmail.com; jordaocm@hotmail.com.

3Professora do Departamento de Química. UFLA - Universidade Federal de Lavras. Caixa Postal 3037 -37200-000 - Lavras, MG. E-mail: bianchi@dqi.ufla.br

${ }^{4}$ Professor Titular do Departamento de Ciências Florestais. UFLA - Universidade Federal de Lavras - Caixa Postal 3037 37200-000 - Lavras, MG, 37200-000. E-mail: trugilho@dcf.ufla.br

${ }^{5}$ Doutorando em Química no Programa de Pós-graduação Multicêntrico. UFLA - Universidade Federal de Lavras - Caixa Postal 3037 -37200-000 - Lavras, MG, 37200-000. E-mail: ocadil@hotmail.com
}

Sci. For., Piracicaba, v. 43, n. 108, p. 895-906, dez. 2015 DOI: dx.doi.org/10.18671/scifor.v43n108.14 
Gorgulho et al. (2008) mencionaram que o CA é um material carbonáceo de estrutura porosa e apresenta pequena quantidade de heteroátomos, principalmente oxigênio, ligado aos átomos de carbono. É um material que possui área superficial específica e porosidade elevada, o que lhe confere a capacidade de adsorver moléculas presentes tanto em fase líquida como gasosa. Schetino Jr. et al. (2007) informaram que o CA possui alta capacidade de adsorção, que possibilita ser utilizado na recuperação de produtos químicos, remoção de compostos orgânicos e metais, remoção de contaminantes presentes em meio aquoso, em processo de purificação, desodorização do ar, tratamento d'água, refino do açúcar, como suporte para catalisadores e outros.

Mesmo com sua alta taxa de utilização, o CA ainda é um material de custo elevado. Precursores de biomassa são mais baratos, renováveis e se encontram acessíveis abundantemente (DIN et al., 2009). Na região Amazônica, o processamento de 14,2 milhões de $\mathrm{m}^{3}$ de tora resultaram em 5,8 milhões de $\mathrm{m}^{3}$ de madeira serrada. Sendo 8,4 milhões de $\mathrm{m}^{3}$ qualificados como resíduos do processamento e apenas 6,3 milhões de $\mathrm{m}^{3}$ de resíduos são aproveitados (carvão vegetal, geração de energia e usos diversos). Os 2,1 milhões de $\mathrm{m}^{3}$ restantes são resíduos sem nenhum aproveitamento, sendo queimados ou abandonados como entulho (IMAZON, 2010).

A utilização de resíduos de madeira, como a serragem, para produzir carvão ativado é vantajosa, pois, além da disponibilidade e baixo custo, já se encontra em uma granulometria desejável (pó), possuindo uma área superficial específica inicial maior. Outra vantagem da utilização do resíduo é a grande quantidade de matéria-prima para a indústria de carvão ativado e a grande demanda pelo produto (COUTO et al., 2012). Portanto, o objetivo deste trabalho foi produzir carvão ativado de resíduos de Apuleia leiocarpa e verificar as propriedades do carvão produzido.

\section{MATERIAL E MÉTODOS}

\section{Matéria-prima}

Foram utilizados resíduos de madeira na forma de serragem da espécie Apuleia leiocarpa (Vogel) J.F. Macbr, usualmente conhecida como garapa, provenientes do município de Uruará, Estado do Pará, Brasil. Este município se localiza a 03 ${ }^{\circ} 43^{\prime} 03^{\prime \prime}$ de latitude sul e $53^{\circ} 44^{\prime} 12^{\prime \prime}$ de longitude oeste, distante a aproximadamente $1000 \mathrm{Km}$ da capital do Belém.

A serragem bruta foi coletada, peneirada e classificada nas granulometrias de 40, 60, 100, 200 e 270 mesh, após o peneiramento a serragem foi colocada em saco plástico e acondicionada em sala de climatização, à temperatura de $20 \pm 2{ }^{\circ} \mathrm{C}$ e umidade de $65 \pm 3 \%$, até atingir massa constante e umidade média de $12 \%$. Também foi realizada a distribuição granulométrica após o peneiramento para verificação do rendimento em cada peneira.

Para as análises químicas de quantificação da lignina, componentes secundários totais (extrativos) e constituintes inorgânicos (minerais), foi utilizada a fração retida na peneira de 60 mesh proveniente do processo de peneiramento, realizadas de acordo com as normas da Associação Brasileira de Normas Técnicas - ABNT NBR 14853, NBR 7989 e NBR 13999 de 2003 (ANBT, 2003) e 2010 (ABNT, 2010). A determinação do teor de holocelulose seguiu o método de Browning (1981). O teor de celulose foi determinado por meio da metodologia descrita por Kennedy et al. (1987). A determinação do teor de hemiceluloses foi feita pela diferença da holocelulose e da celulose. A análise elementar para quantificação dos teores de carbono, hidrogênio, nitrogênio e enxofre (CHNS-O) do material foi realizada por meio de um analisador simultâneo de elementos (Elementar Vario Micro cube). O teor de oxigênio foi obtido por diferença.

\section{Produção do carvão vegetal}

Para a produção dos carvões vegetais foram utilizadas as serragens que ficaram retidas no jogo de peneiras 40-60 mesh. Utilizaram-se aproximadamente $80 \mathrm{~g}$ de serragem por cada pirólise, sendo distribuída dentro de quatro cadinhos de porcelana no reator de pirólise.

Em seguida as serragens foram pirolisadas em forno tipo mufla, adaptado para essa atividade, do Laboratório de Bioenergia do DCF/UFLA. A taxa de aquecimento utilizada foi de $100^{\circ} \mathrm{C} . \mathrm{h}^{-1}$, indicada para produção de carvão vegetal e em temperatura final de $500^{\circ} \mathrm{C}$, com tempo de residência de 30 minutos na temperatura final. O resfriamento ocorreu de forma natural e gradativa após o forno atingir a temperatura final de carbonização. Também foi determinado o rendimento gravimétrico da carbonização. 


\section{Preparo do carvão ativado}

A ativação física dos carvões vegetais foi realizada em forno elétrico do tipo cilíndrico. O processo de ativação dos carvões foi efetuado à temperatura final de $850^{\circ} \mathrm{C}$ (com taxa de aquecimento de $10^{\circ} \mathrm{C} \cdot \mathrm{min}^{-1}$ ), durante $60 \mathrm{~min}$ (tempo de residência na temperatura final) utilizando-se fluxo de $150 \mathrm{~mL} \cdot \mathrm{min}^{-1}$ de $\mathrm{CO}_{2}$ como agente ativante. Foi utilizado aproximadamente $1 \mathrm{~g}$ de carvão vegetal precursor em cada barqueta de porcelana, sendo sete barquetas por ativação, conseguindo assim obter quantidade suficiente de CA para realização das análises. Este procedimento foi realizado no Laboratório de Catálise e Química Ambiental do Departamento de Química - DQI da UFLA.

\section{Caracterização do carvão vegetal}

Para quantificação dos teores de carbono, hidrogênio, nitrogênio e enxofre dos carvões vegetais realizou-se a análise elementar (CHNS-O) por meio de um analisador simultâneo de elementos (Elementar Vario Micro cube). O teor de oxigênio foi obtido por diferença.

\section{Caracterização do carvão ativado}

As isotermas de adsorção e dessorção de $\mathrm{N}_{2}$ dos carvões ativados produzidos foram obtidas a 77 $\mathrm{K}$ em um equipamento AUTOSORB-1 Quantachrome. A área superficial específica foi determinada a partir da isoterma de adsorção, usando o método multiponto BET - Brunauer/Emmett/Teller (BRUNAUER et al., 1938). A faixa de pressão relativa utilizada foi a descrita pelo manual de operação do aparelho autosorb1 para carvão ativado (QUANTACHROME, 2006). O volume de poros e distribuição foi obtido a partir da isoterma de adsorção/dessorção de nitrogênio, utilizando o modelo de teoria para densidade funcional para poros e fendas - DFT (WEBB; ORR, 1997; DUNNE et al., 2010). Os teores de carbono, hidrogênio, nitrogênio e enxofre (CHNS-O) dos carvões ativados foram determinados por meio de um analisador simultâneo de elementos (Elementar Vario Micro cube). O teor de oxigênio foi obtido por diferença.

\section{Testes de adsorção}

\section{Isotermas de adsorção}

Para a determinação das isotermas de adsorção dos CAs foram utilizados compostos orgânicos azul de metileno e fenol. Foram utilizados $10 \mathrm{mg}$ de CA em $10 \mathrm{~mL}$ das soluções com diferentes concentrações $\left(25,50,100,250,500\right.$ e $\left.1000 \mathrm{mg}^{-L^{-1}}\right)$, onde foram inseridos em um em frascos âmbar de $25 \mathrm{~mL}$ e foram mantidos sob agitação a $100 \mathrm{rpm}$ em uma chapa agitadora por 1440 minutos (24 horas), com variações de temperatura do próprio ambiente, não havendo controle do mesmo, podendo influenciar no processo de adsorção. Para a determinação da concentração de equilíbrio foi realizada por curvas analíticas, onde foram retiradas alíquotas das soluções de aproximadamente 3,5 mL e mensuradas utilizando espectroscopia de UV-Visível (Applied Biosystems, modelo SP-2000 de UV) para o azul de metileno $(\lambda=665 \mathrm{~nm})$ e fenol $(\lambda=270 \mathrm{~nm})$ em análise pontual de absorbância, ou seja, não foi feita leitura por varredura.

Os dados das isotermas de equilíbrio foram ajustados segundo os modelos de Langmuir (1) e de Freundlich (2) (SENTHILKUMAAR et al, 2006; KUMAR; SIVANESAN, 2006).

Em que $\mathrm{C}_{e}$ é a concentração da solução no equilíbrio ( $\mathrm{mg}$. $\mathrm{L}^{-1}$ ), qm é a capacidade máxima de adsorção; $\mathrm{K}_{\mathrm{L}}$ é a constante de Langmuir; $\mathrm{K}_{\mathrm{F}}$ e n são os coeficientes de Freundlich e $\mathrm{R}^{2}$ é o coeficiente de correlação.

$$
\begin{aligned}
& q_{e q}=\frac{q m K_{L} C_{e}}{1+K_{L} C_{e}} \\
& q_{e}=K_{F} C_{e}^{\frac{1}{n}}
\end{aligned}
$$

Os valores de $\mathrm{q}_{\mathrm{m}}$ e $\mathrm{K}_{\mathrm{F}}$ permitem avaliar a capacidade de adsorção, identificando a capacidade do carvão ativado de reter determinado soluto, o que possibilita estimar extensão de seu movimento na fase líquida. Estes coeficientes podem ser entendidos como uma medida da distribuição de equilíbrio entre as fases sólida e líquida. Assim sendo, quanto maior a capacidade adsortiva do material, maiores serão os valores de $\mathrm{q}_{\mathrm{m}}$ e $\mathrm{K}_{\mathrm{F}}$ para os modelos de Langmuir e Freundlich, respectivamente. 


\section{Cinéticas de adsorção}

Para os estudos de cinética de adsorção foram utilizados $10 \mathrm{mg}$ de carvão ativado e $10 \mathrm{~mL}$ de soluções de azul de metileno e fenol, nas concentrações de $50 \mathrm{mg}$. $\mathrm{L}^{-1}$. Em intervalos predeterminados de $0 ; 5 ; 10 ; 15 ; 30 ; 60 ; 120 ; 180 ; 360 ; 540 ; 1.200 ; 1.440$ e 2.880 minutos (48 horas), foram retiradas alíquotas das soluções de aproximadamente $3,5 \mathrm{~mL}$ e suas concentrações determinadas por UV-visível. O estudo da cinética de adsorção foi realizado para a determinação do tempo necessário para se atingir o equilíbrio de adsorção.

\section{Morfologia superficial}

A morfologia superficial dos CAs foi obtida por microscopia eletrônica de varredura (MEV), em um aparelho LEO EVO 40XVP, empregando tensão de $25 \mathrm{kV}$. As amostras foram montadas sob uma plataforma de alumínio, utilizando-se fita de carbono dupla faces e em seguida, cobertas com uma fina camada de carbono em evaporador Balzers SCD 050. Foram obtidas fotos micrografias, após a carbonização (carvão vegetal) e após a ativação (carvão ativado), para visualização da alteração na morfologia superficial desses materiais.

\section{RESULTADOS E DISCUSSÃO}

Os valores médios da composição química, composição elementar e rendimento granulométrico após o peneiramento da serragem da madeira de Apuleia leiocarpa encontram-se na Tabela 1.

Tabela 1. Composição química, composição elementar e rendimento granulométrico (peneiramento) da serragem de Apuleia leiocarpa.

Table 1. Chemical composition, elemental composition and graded yield (by sieving) of Apuleia leiocarpa sawdust.

\begin{tabular}{lc}
\hline & Madeira de Garapa - Densidade aparente: $\mathbf{0 , 8 8 0 ~} \mathbf{~ g . c m}^{-3}$ \\
\hline Composição química & Quantidade (\%) \\
\hline Lignina & 29,50 \\
Extrativos & 10,05 \\
Minerais & 1,93 \\
Holocelulose & 73,75 \\
\hline \multicolumn{1}{c}{ Composição elementar } \\
\hline H & \\
N & 48,48 \\
S & 5,60 \\
$-O$ & 0,85 \\
O/C & 0,02 \\
\hline & 45,04 \\
\hline 40 mesh & 0,93 \\
60 mesh & \\
100 mesh & Rendimento granulométrico \\
200 mesh & 35,71 \\
270 mesh & 34,77 \\
\hline
\end{tabular}

\section{Composição química, elementar e rendimento granulométrico da serragem}

$\mathrm{Na}$ análise química, foram encontrados valores médios de 29,50\% de lignina, 10,05\% de extrativos, 73,75\% para holocelulose e teor de cinza abaixo de 2\% (1,93\%). Santana e Okino (2007) ao realizar análise química com a mesmas espécie, encontraram valores semelhantes $(28,20 \%, 9,40 \%$, $71,80 \%$ e $1,60 \%$ respectivamente). Isso demonstra a coerência dos dados obtidos e indica que esse material possui características químicas e quantidade de carbono suficiente para se preparar carvão ativado. A análise elementar CHNS-O revelou que a serragem da espécie Apuleia leiocarpa (Vogel) J.F. Macbr possui relativamente elevado teor de carbono (48,48\%). A quantidade de carbono da espécie demonstra o potencial que esta possui para se tornar uma estrutura carbonácea altamente porosa. É importante ressaltar que matérias-primas com maiores teores de carbono e menores teores de cinzas podem ser consideradas mais aptas na produção de carvão ativado (CHEN et al., 2013). Portanto, os resultados (Tabela 1) sugerem que a serragem utilizada é adequada para a produção de carvão ativado. 
A distribuição granulométrica, após o peneiramento das serragens apresentou maior rendimento na peneira de 60 mesh, que correspondeu a 34,77\% (Tabela 1). Os maiores rendimentos por granulometria foram observados nas peneiras de 40, 60 e 100 mesh, salientando para o maior rendimento na peneira de 60 mesh, indicando um bom resultado, pois é uma das granulometrias mais utilizadas para análises químicas e produção do CA pulverizado.

\section{Rendimento gravimétrico e composição elementar do carvão vegetal}

Na Tabela 2 encontram-se os valores médios do rendimento gravimétrico e composição elementar do carvão vegetal produzido da madeira de Apuleia leiocarpa.

Tabela 2. Rendimento gravimétrico da carbonização e composição elementar do carvão vegetal de Apuleia leiocarpa. Table 2. The carbonization gravimetric yield and elemental composition of Apuleia leiocarpa charcoal.

\begin{tabular}{lc}
\hline Parâmetros & Valores \\
\hline Rendimento em carvão vegetal (\%) & 33,82 \\
\hline Composição elementar & \\
\hline C (\%) & 74,26 \\
H (\%) & 2,57 \\
N (\%) & 0,46 \\
S (\%) & 0,02 \\
$-O(\%)$ & 22,67 \\
O/C & 0,30 \\
\hline
\end{tabular}

Nota-se na Tabela 2 que o rendimento foi consideravelmente alto (acima de 30\%) quando se compara ao rendimento em carvão de madeira sólida. Isto se deve ao fato da espécie possuir quantidade significativa de lignina, o que dá mais resistência ao material durante o processo de carbonização e também ao alto teor de carbono presente no material. Outro fator é o teor de oxigênio, que também contribui para o rendimento em carvão, o menor teor de oxigênio possibilita menor combustão do material durante seu processo de carbonização. O carvão vegetal produzido possui alto teor de carbono $(74,26 \%)$ o que resultará na formação de uma área de superfície elevada com um elevado volume de poros no carvão ativado.

\section{Rendimento gravimétrico e composição elementar do carvão ativado}

Os valores médios do rendimento e composição elementar do carvão ativado da madeira de Apuleia leiocarpa encontram-se na Tabela 3.

Tabela 3. Rendimento e características dos carvões ativados de Apuleia leiocarpa.

Table 3. Yield and characteristics of activated carbons of Apuleia leiocarpa.

\begin{tabular}{lc}
\hline Parâmetros & Valores \\
\hline Rendimento em carvão ativado (\%) & 72,52 \\
$\mathrm{C}(\%)$ & 85,38 \\
$\mathrm{H}(\%)$ & 1,60 \\
$\mathrm{~N}(\%)$ & 1,72 \\
$\mathrm{~S}(\%)$ & 0,03 \\
$-\mathrm{O}(\%)$ & 11,25 \\
O/C & 0,13 \\
BET área específica $\left(\mathrm{m}^{2} \cdot \mathrm{g}^{-1}\right)$ & 564,90 \\
\hline
\end{tabular}

Pela análise da Tabela 3 observa-se que o carvão ativado produzido possui alto teor de carbono $(85,38 \%)$. Esses valores são decorrentes da ativação física que utiliza altas temperaturas $\left(850^{\circ} \mathrm{C}\right) \mathrm{e}$ do fluxo de $\mathrm{CO}_{2}$ liberando uma maior quantidade de compostos por volatilização. Quando comparados aos materiais precursores, nota-se que o teor de carbono aumenta e os teores de hidrogênio, nitrogênio, oxigênio e enxofre foram reduzidos nos carvões produzidos. Isto ocorre devido à liberação de substâncias voláteis durante a pirólise, a qual pode resultar na eliminação dos elementos não carbonados (AVELAR et al., 2010). Couto et al. (2012) ao utilizarem serragem de eucalipto na preparação de carvão ativado com $\mathrm{CO}_{2^{\prime}}$ encontrou teor de carbono de 89,3\% e 8,61\% de oxigênio. 


\section{Área superficial BET}

Os valores médios da caracterização textural do carvão ativado, por meio da área superficial BET podem ser observados na Tabela 3. O CA de Garapa apresentou área superficial de 564,90 $\mathrm{m}^{2} \cdot \mathrm{g}^{-1}$.

As isotermas de adsorção e dessorção de nitrogênio para a espécie (Figura 1) apresentaram elevada adsorção de $\mathrm{N}_{2}$ em baixas pressões relativas, indicando assim que a natureza do carvão é predominantemente microporosa. Os carvões ativados microporosos proporcionam alta capacidade de adsorção de moléculas de dimensões pequenas, como exemplo, gases e diversos tipos de solventes.

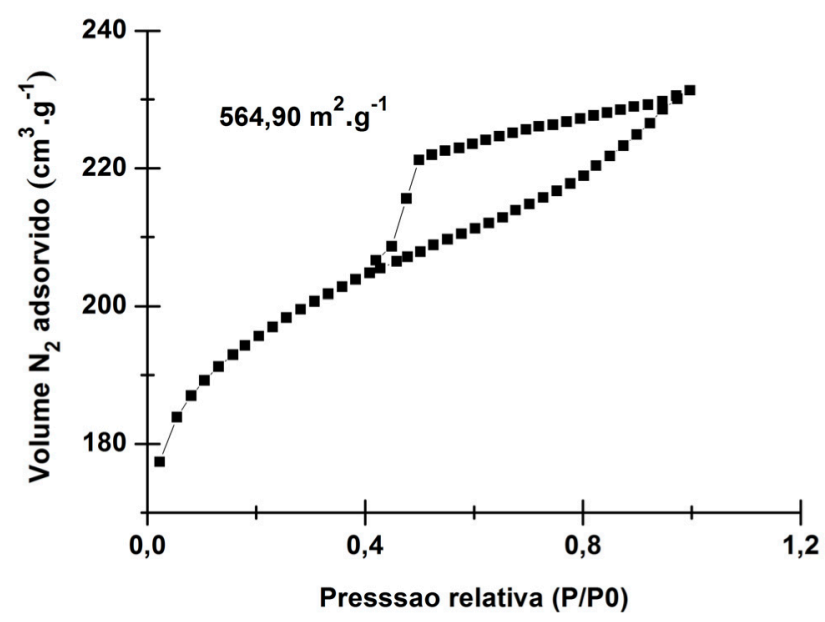

Figura 1. Isotermas de adsorção/dessorção de nitrogênio, a 77 K, para carvão ativado de Apuleia leiocarpa. Figure 1. Isotherms of adsorption/desorption of nitrogen at $77 \mathrm{~K}$ for activated Apuleia leiocarpa carbon.

O desenvolvimento de mesoporosidade é mais desejável do que a produção de microporos para aplicações em fase líquida, tais como a adsorção de ácidos orgânicos (YANG, 2003). O CA de Garapa possui pequena quantidade e volume de mesoporos, porém quando comparado a valores encontrados na literatura, tratando de outros carvões, são resultados satisfatórios. Este desenvolvimento de mesoporos, apesar de quantidade pequenas, pode estar associado à destruição das paredes internas existentes entre dois microporos, devido à alta taxa de temperatura de ativação $\left(850^{\circ} \mathrm{C}\right)$, somado a estrutura anatômica (vasos, poros, fibras, pontoações, etc.) da serragem, tornando-os assim somente em um poro de dimensão maior.

Os diferentes valores para áreas de superfície e as diferenças entre as porosidades dos carvões ativados podem ser atribuídos às características anatômicas dos materiais estudados (MARSH; RODRÍGUEZ-REINOSO, 2006). Couto et al. (2012) ao utilizarem serragem de eucalipto para produção física e química de carvão ativado encontraram uma área de $528,33 \mathrm{~m}^{2} \cdot \mathrm{g}^{-1}$ e características de um carvão ativado microporoso. Com isso pode-se ressaltar que espécies florestais com madeiras de densidades mais elevadas podem alcançar áreas superficiais mais altas as do que espécies florestais com madeiras de menor densidade.

\section{Testes de adsorção}

Na Tabela 4 encontram-se os valores médios da adsorção de azul de metileno e fenol pelo carvão ativado de Apuleia leiocarpa. O estudo da cinética de adsorção mostra uma rápida adsorção (15 min.) para o composto fenol isso ocorre devido ao preenchimento dos sítios ativos do adsorvente, atingindo o equilíbrio após 500 minutos de adsorção (Figura 2). Já para azul de metileno não foi evidenciando o equilíbrio no final da análise, após o tempo de $2880 \mathrm{~min}$. de contato, o material continuou adsorvendo. Comparando o gráfico da isoterma com o da cinética (Figura 2 e 3), verifica-se que na concentração de $50 \mathrm{mg} . \mathrm{L}^{-1}$, adsorção após $1440 \mathrm{~min}$. (24 h) foram de aproximadamente 25 mg.L. $\mathrm{L}^{-1}$. Sendo assim, talvez seria necessário um tempo maior para adsorção entrar em equilíbrio, mostrando a capacidade de adsorção do CA para o composto azul de metileno na concentração de $50 \mathrm{mg} . \mathrm{L}^{-1}$. O não equilíbrio na adsorção, também, pode ser influenciado por mudanças de temperaturas do ambiente nos intervalos de tempo do experimento. 
Tabela 4. Parâmetros Langmuir e Freundlich para a adsorção de azul de metileno e fenol dos carvões ativados de garapa.

Table 4. Langmuir and Freundlich parameters for the adsorption of methylene blue and phenol of garapa activated carbons.

\begin{tabular}{lccc|ccc}
\hline \multirow{2}{*}{ Compostos } & \multicolumn{3}{c|}{ Langmuir } & \multicolumn{3}{c}{ Freundlich } \\
\cline { 2 - 7 } & $\mathbf{q}_{\text {max }}\left(\mathbf{m g} \cdot \mathbf{g}^{-1}\right)$ & $\mathbf{K}_{\perp}\left(\mathbf{L} \cdot \mathbf{m g}^{-1}\right)$ & $\mathbf{R}^{\mathbf{2}}$ & $\mathbf{1 / n}$ & $\mathbf{K F}\left(\mathbf{m g ~ L}^{-1}\right)\left(\mathbf{L} \mathbf{~ m g ~}^{-1}\right)^{\mathbf{1 / n}}$ & $\mathbf{R}^{\mathbf{2}}$ \\
\hline Azul de metileno & 400,78 & 0,01 & 0,92 & 0,480 & 17,17 & 0,96 \\
Fenol & 329,19 & 0,01 & 0,91 & 0,316 & 41,93 & 0,99 \\
\hline
\end{tabular}

$\mathrm{q}_{\max }=$ Quantidade máxima de $\left(\mathrm{mg} \cdot \mathrm{g}^{-1}\right) ; \mathrm{K}_{\mathrm{L}}=$ Constante Langmuir (L.mg-1 $) ; \mathrm{R}^{2}$ = coeficiente de correlação;

$\mathrm{KF}=$ Constante Freundlich $\left[\left(\mathrm{mg} \mathrm{L}^{-1}\right)\left(\mathrm{L} \mathrm{mg}^{-1}\right)^{1 / n}\right] ; \mathrm{I} / \mathrm{n}=$ parâmetro Freundlich

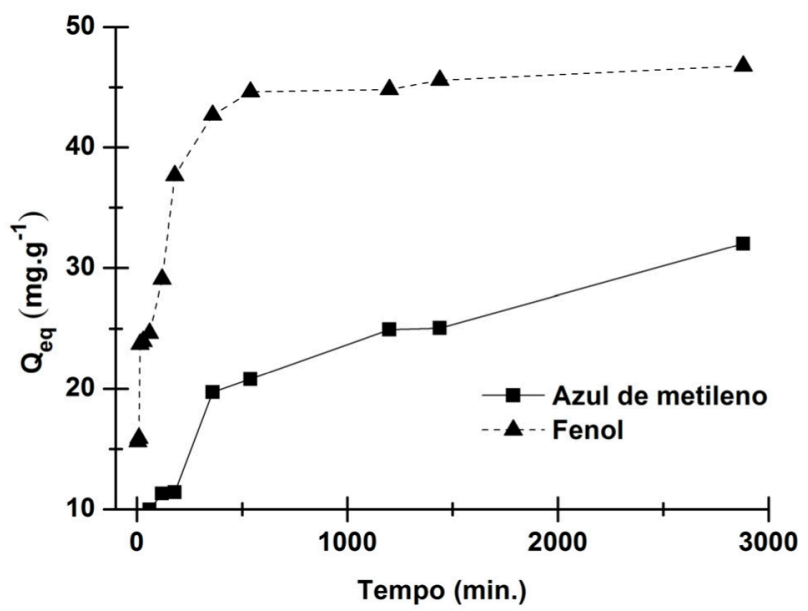

Figura 2. Cinéticas de adsorção de Azul de metileno e Fenol em CA de Apuleia leiocarpa (10 mg de CA; $10 \mathrm{~mL}$ de solução em concentração de 50 ppm; temperatura ambiente).

Figure 2. Kinetics of adsorption of Methylene blue and Phenol in AC of Apuleia leiocarpa (10 mg of AC, $10 \mathrm{~mL}$ of solution in a concentration of $50 \mathrm{ppm}$; ambient temperature).

O corante catiônico azul de metileno é um composto modelo utilizado para a adsorção de compostos orgânicos de tamanho médio, em soluções aquosas (STAVROPOULOS; ZABANIOTOU, 2005).

A velocidade em que ocorreu a adsorção pode estar relacionada com os sítios de adsorção disponíveis na superfície do carvão, seguido de um processo mais lento (BUENO; CARVALHO, 2007).

Avelar et al., 2010, estudando as propriedades de carvões ativados a partir de fibras de piaçava encontraram adsorção para azul de metileno, para carvões ativados quimicamente com $\mathrm{ZnCl}_{2}$ $\left(\mathrm{CA} \mathrm{ZnCl}_{2}\right)$ fisicamente com $\mathrm{CO}_{2}\left(\mathrm{CA} \mathrm{CO}_{2}\right)$ e comercial (CA comercial), de 276,40 mg.g ${ }^{-1}, 34,87$ e 179,46, respectivamente. Os mesmos autores encontraram área superficial de 1190 e $475 \mathrm{~m}^{2} \mathrm{~g}^{-1}$ para CA $\mathrm{ZnCl}_{2}$ e CA CO${ }_{2}$, respectivamente. Couto et al., 2012, avaliando as propriedades do carvão ativado produzido a partir de serragens de Eucalyptus sp., e ativado via processo físico com $\mathrm{CO}_{2^{\prime}}$ encontraram adsorção máxima para azul de metileno de $32 \mathrm{mg} \cdot \mathrm{g}^{-1}$ e área superficial $528,33 \mathrm{~m}^{2} \cdot \mathrm{g}^{-1}$.

A remoção dos compostos pelo CA foi elevada, quando comparada com os autores supracitados, provavelmente devido à área superficial $\left(564,90 \mathrm{~m}^{2} \cdot \mathrm{g}^{-1}\right)$, química de superfície e a quantidade significativa de mesoporos encontrados.

As isotermas de adsorção do azul de metileno e fenol para o CA são apresentadas na Figura 3.

Verifica-se na Figura 3-A, os valores observados de adsorção, que o CA mostrou-se eficiente na adsorção de azul de metileno O CA apresentou adsorção superior a $350 \mathrm{mg} \cdot \mathrm{g}^{-1}$ para azul de metileno, isto está relacionada à presença significativa de mesoporos e microporos secundários, sendo estas estruturas um fator determinante para adsorção de moléculas médias e grandes, como é o caso da molécula de azul de metileno (XUN et al., 2007; BESTANI et al., 2008). Isso evidencia a eficiencia do CA preparado a partir de resíduos de Apuleia leiocarpa, que pode ser capaz de remover soluções altamente concentradas e obter remoção parcial dessas.

Os parâmetros de Langmuir e Freundlich para o composto azul de metileno são observados na Tabela 4. Comparando-se o $\mathrm{R}^{2}\left(\mathrm{Q}_{\mathrm{e}} \mathrm{vs}_{\mathrm{e}}\right)$ valores para a os modelos de Langmuir e Freundlich, o CA é mais ajustado para o modelo de Freundlich, indicando a adsorção em multicamadas. 

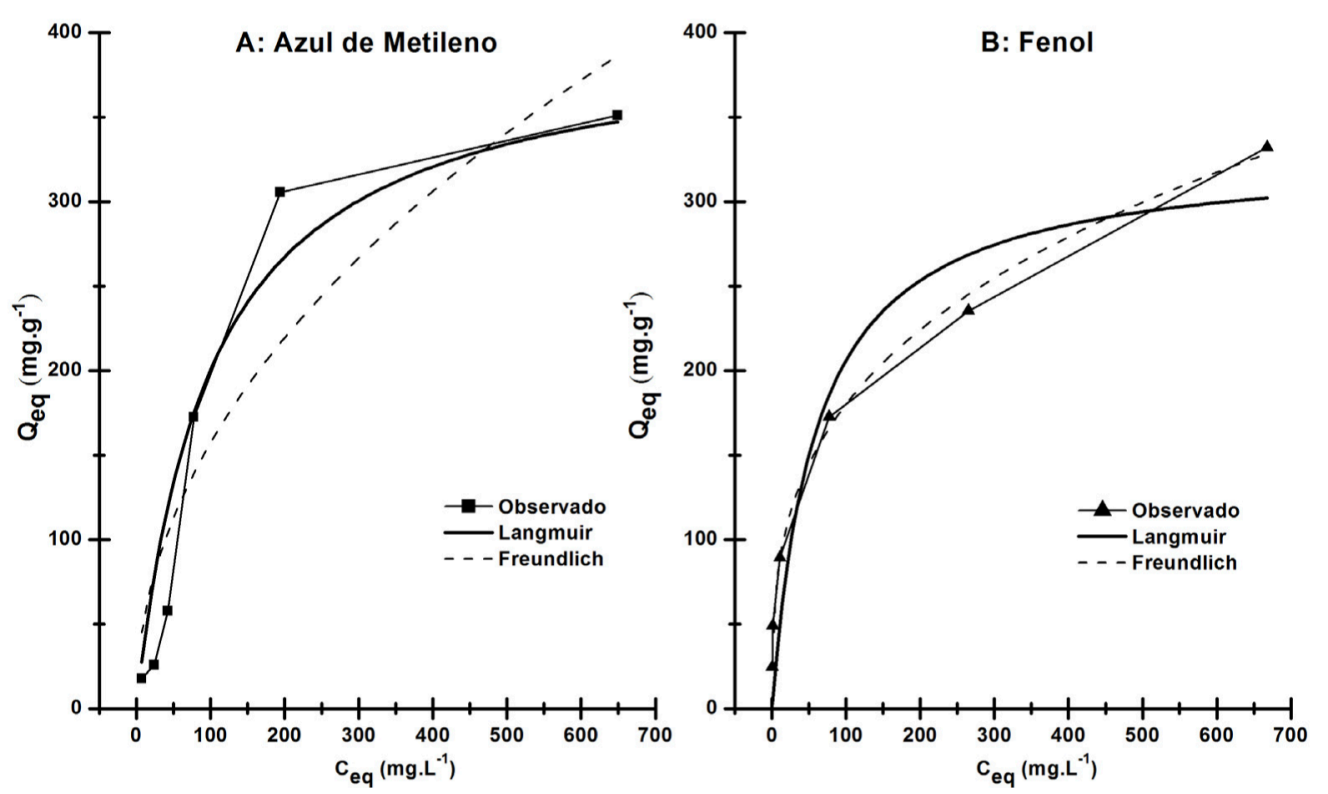

Figura 3. Isotermas de adsorção em CA de Apuleia leiocarpa (10 mg de $C A ; 10 \mathrm{~mL}$ de solução em diferentes concentrações; temperatura ambiente); A - Azul de Metileno; B - Fenol.

Figure 3. Isotherms of adsorption in $A C$ of Apuleia leiocarpa (10 mg of $A C, 10 \mathrm{~mL}$ of solution at different concentrations, ambient temperature): A - Methylene blue; B - Phenol.

Small et al. (2012) ao caracterizarem carvão ativado fisicamente a partir de "oil sands coke", encontraram baixos valores de remoção de azul de metileno, variando de 2 a 9 mg.g ${ }^{-1}$, com área de superfície de $577,5 \mathrm{~m}^{2} \cdot \mathrm{g}^{-1}$. Os mesmos autores associaram a baixa adsorção às características microporosas encontradas nos carvões produzidos. Brum et al. (2008) encontraram adsorção máxima de azul de metileno em carvão ativado produzido a partir de resíduos do beneficiamento do café, de aproximadamente de $188,7 \mathrm{mg} \cdot \mathrm{g}^{-1}$.

O Fenol é utilizado como um soluto para estudos de adsorção em fase líquida e também para determinar a área superficial específica de materiais adsorventes e carvões ativados (NEVSKAIA et al., 1999). A adsorção de fenol ocorre em poros classificados como ultramicroporos (diâmetro menor que $0,7 \mathrm{~nm}$ ) e microporos (diâmetro menor que $2 \mathrm{~nm}$ ), os quais são maiores que o diâmetro molecular do fenol, que é de 0,62 nm (DAIFULLAH; GIRGIS, 1998).

Verifica-se na Figura 3-B que o CA também apresentou capacidade de adsorção para o fenol. O CA preparado com a serragem obteve adsorção máxima superior a $300 \mathrm{mg}$. $\mathrm{g}^{-1}$. Ficou comprovado que esses valores estão associados à natureza microporosa do carvão ativado produzido. Quanto maior o volume de microporos existentes maior será a quantidade de fenol adsorvido, por se tratar de uma molécula com diâmetro menor que $2 \mathrm{~nm}$.

Os parâmetros de Langmuir e Freundlich para o composto fenol são observados na Tabela 4, onde verifica-se no que o CA apresenta $\mathrm{q}_{\max }$ de $329,19 \mathrm{mg} \cdot \mathrm{g}^{-1}$, conforme observado no parâmetro Langmuir. Assim como para o azul de metileno, o modelo mais ajustado é o de Freundlich.

Outro fator a se ressaltar e que pode explicar o alto poder de adsorção de fenol, porém que não pode ser considerado de extrema importância é em relação à química de superfície do carvão ativado e também a quantidade de grupos de oxigênio existentes nestes carvões. É recomendável a realização de estudos mais detalhados para correlacionar a significância destes grupos oxigênios e química de superfície com a adsorção de fenol.

Hameed e Rahman (2008) estudaram a remoção de fenol em carvão ativado preparados com serragens de rattan e verificaram adsorção máxima de 149,25 mg.g ${ }^{-1}$. Din et al. (2009) verificaram que a capacidade de adsorção de fenol em carvões ativados de casca de coco foi 205,8 mg. ${ }^{-1}$. Avelar et al. (2010) utilizaram fibras de piaçava (Attalea funifera Mart.) na preparação de carvões ativados e obtiveram resultados para adsorção de fenol em carvão ativado fisicamente com $\mathrm{CO}_{2}$ de, aproximadamente, $120 \mathrm{mg}^{-1}$. 
Girods et al. (2009) estudaram a caracterização de carvões ativados produzidos a partir de resíduos de painéis de madeira e sua capacidade de adsorção de fenol. O carvão ativado de resíduos de painéis são adsorventes com capacidade máxima de adsorção próxima de $500 \mathrm{mg} \cdot \mathrm{g}^{-1}$.

Verificou-se (Figura 3) que o carvão ativado produzido foi bastante eficiente na adsorção de fenol e azul de metileno, sendo mais eficiente do que outros carvões ativados obtidos por outros autores, com materiais de diversas naturezas. Tal fato demonstra a alta qualidade dos resíduos de Apuleia leiocarpa, que podem ser considerados uma fonte promissora de matéria-prima para a produção de carvão ativado.

\section{Morfologia superficial}

Nas micrografias, observa-se que a morfologia do carvão vegetal precursor foi modificada após o processo de ativação (Figura 4). A análise de microscopia eletrônica de varredura permitiu verificar a superfície porosa que pode ter sido formada pela intensa eliminação de voláteis nas reações secundárias da estrutura da biomassa.

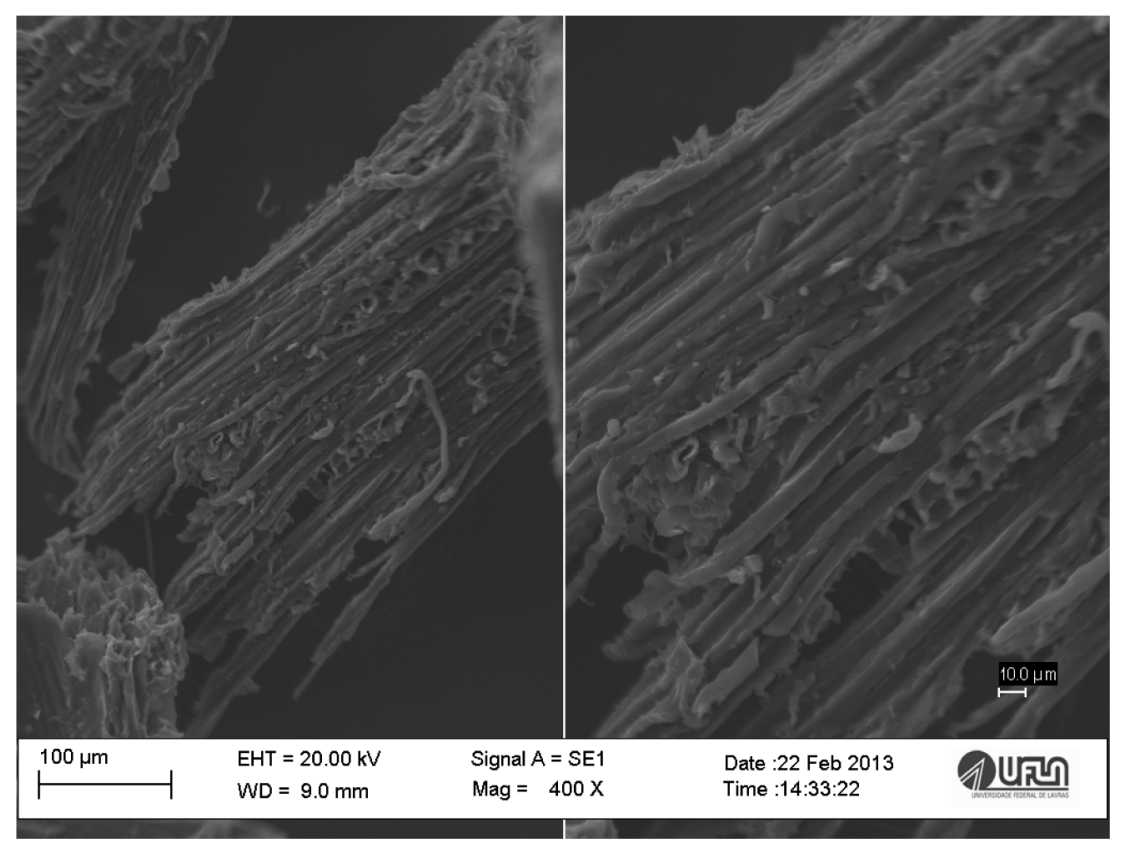

(a)

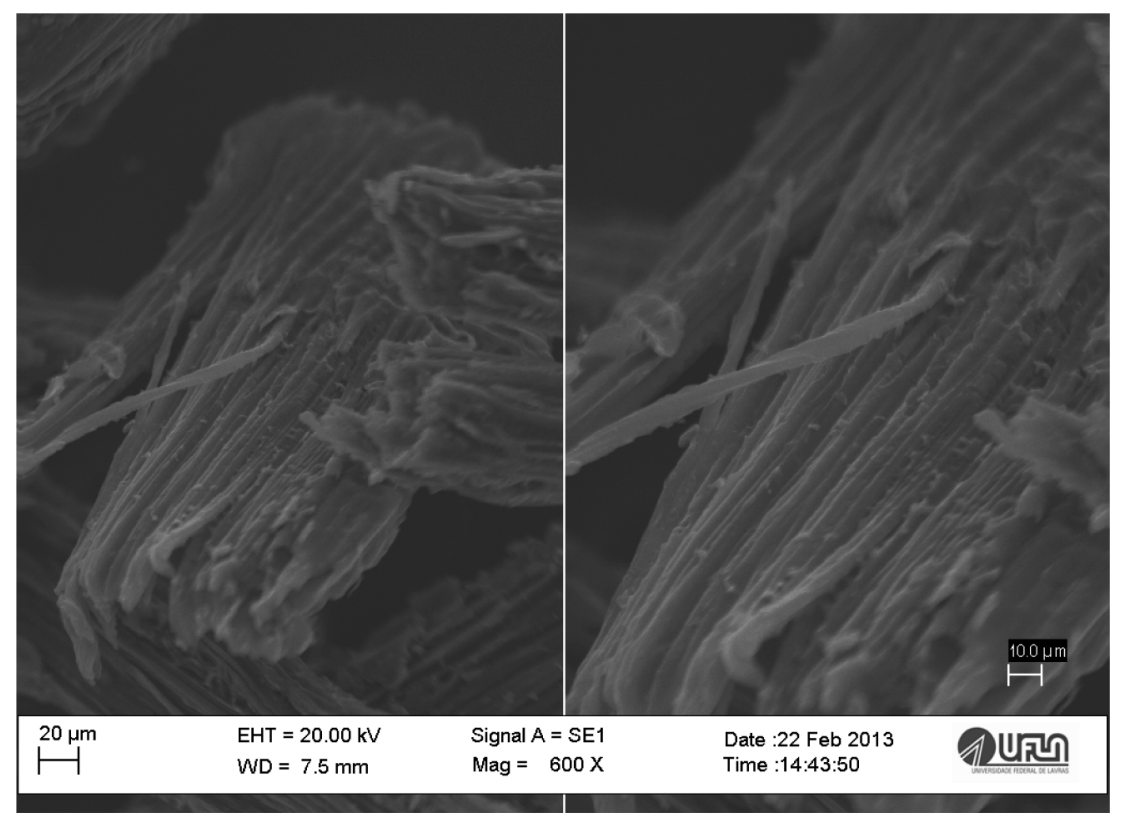

(b)

Figura 4. Fotomicrografias do carvão precursor (a) e carvão ativado (b) de Apuleia leiocarpa.

Figure 4. Photomicrographs of the precursor coal (a) and activated carbon (b) of Apuleia leiocarpa. 
Observa-se na Figura 4 o destacamento de várias fibras em consequência da ativação proposta. Isso promoveu um aumento da capacidade de adsorção do carvão devido ao aparecimento de fissuras entre as fibras, que podem funcionar como vias de acesso para adsorver maior quantidade de reagentes. Couto et al. (2012) também observaram o aumento no número de poros e a ocorrência de mudanças na morfologia do carvão vegetal precursor após a ativação. Os autores também verificaram o aumento do número de meso e macroporos após a ativação.

Chen e Hashisho (2012) e Small et al. (2012), ao ativarem fisicamente "oil sands coke" também observaram mudança na morfologia superficial do material. Os autores observaram que o material bruto possuía um número limitado de cavidades e após a ativação este número de cavidades aumentou. A ativação também provocou o aparecimento de grandes fendas no material, provavelmente estendendo-se até a parte interna do coque. Assim, foram formados mais canais para acessar os microporos e mesoporos dentro de uma partícula de coque. Essas mesmas observações podem ser retratadas no presente trabalho, em que se verificou a formação de espaços vazios que contribuíram para aumentar o acesso aos micro e mesoporos, aumentando assim o poder de adsorção do carvão ativado.

\section{CONCLUSÕES}

A partir dos valores observados, constatou-se que os resíduos madeireiros de Apuleia leiocarpa (Garapa) apresentam elevado potencial como precursores na produção de carvão ativado (CA), por meio da ativação física $\left(\mathrm{CO}_{2}\right)$. Os resíduos apresentam alto rendimento granulométrico, são fontes de matéria prima que podem ser utilizadas na produção do carvão vegetal e posteriormente serem transformado em carvão ativado.

O carvão vegetal apresentou alto rendimento gravimétrico. O carvão ativado produzido apresentou elevada microporosidade e quantidade significativa de mesoporos além de elevada área superficial. Também apresentou alta capacidade de adsorção dos compostos azul de metileno e fenol.

\section{AGRADECIMENTOS}

Os autores agradecem ao Conselho Nacional de Desenvolvimento Científico e Tecnológico CNPq pela aquisição de equipamentos. À Fundação Amparo à Pesquisa do Estado do Amazonas (FAPEAM) e a Coordenação de Aperfeiçoamento de Pessoal de Nível Superior - CAPES pela concessão de bolsas de estudo. À Fundação de Amparo à Pesquisa do Estado de Minas Gerais - FAPEMIG pela concessão de auxílio para participação no evento e aquisição de equipamentos para produção do trabalho. E por fim à Serraria Marajoara S.A. - SEMASA pelo fornecimento da matéria-prima utilizada.

\section{REFERÊNCIAS BIBLIOGRÁFICAS}

ABNT - ASSOCIAÇÃO BRASILEIRA DE NORMAS TÉCNICAS. NBR 13999: determinação do resíduo (cinza) após a incineração a $525^{\circ} \mathrm{C}$. Rio de Janeiro: ABNT, 2003. 4p.

ABNT - ASSOCIAÇÃO BRASILEIRA DE NORMAS TÉCNICAS. NBR 14853: determinação do material solúvel em etanol-tolueno e em diclorometano e em acetona. Rio de Janeiro: ABNT, 2010. 3p.

AVELAR, F. F.; BIANCHI, M. L.; GONÇALVES, M.; MOTA, E. G. The use of piassava fibers (Attalea funifera) in the preparation of activated carbon. Bioresource Technology. Essex, v. 101, n. 12, p. 4639-4645, 2010.

BRUM, S. S. Preparação e caracterização de carvão ativado produzido a partir de resíduos do beneficiamento do café. Química Nova, São Paulo, v. 31, n. 5, p. 1048-1052, 2008.

BESTANI, B.; BENDERDOUCHE, N.; BENSTAALI, B.; BELHAKEM, M.; ADDOU, A. Methylene blue and iodine adsorption onto an activated desert plant. Bioresource Technology, Essex, v. 99, n. 17, p. 8441-8444, 2008. 
BORGES, F. M. et al. Desenvolvimento e criação de uma unidade produtiva de carvão ativado. In: ENCONTRO NACIONAL DE ENGENHARIA DE PRODUÇÃO, 23, 2003, Ouro Preto. Anais... Ouro Preto: UFOP, 2003.1. CD-ROM.

BROWNING, B.L. The chemistry of wood. New York: J. Wiley \& Sons, 1981. 699p.

BRUNAUER, S.; EMMETT, P. H.; TELLER, E. Adsorption of gases in multimolecular layers. Journal American Chemical Society, v. 60, p. 309-319, 1938.

BUENO, C. I. C.; CARVALHO, W. A. Remoção de chumbo (II) em sistemas descontínuos por carvões ativados com ácido fosfórico e com vapor. Química Nova, São Paulo, v. 30, n. 8, p. 1911-1918, 2007.

CHEN, H.; HASHISHO, Z. Fast preparation of activated carbon from oil sands coke using microwave-assisted activation. Fuel, v. 95, p. 178-182, 2012.

CHEN, W.; LIU, X.; HE, R. L.; LIN, T.; ZENG, Q. F.; WANG, X. G. Activated carbon powders from wool fibers. Powder Technology. v. 234, p. 76-83, 2013.

COUTO, G. M.; DESSIMONI,A. L. A.; BIANCHI, M. L.; PERÍGOLO, D. M.; TRUGILHO, P. F. Use of sawdust Eucalyptus sp in the preparation of activated carbons. Ciência e Agrotecnologia, Lavras, v. 36, n. 1, p. 69-77, 2012.

DAIFULLAH, A. A. M.; GIRGIS, B. S. Removal of some substituted phenols by activated carbon obtained from agricultural waste. Water Research, Oxford, v. 32, n. 4, p. 1169-1177, 1998.

DIN, A. T. M.; HAMEED, B. H.; AHMAD, A. L. Batch adsorption of phenol onto physiochemical-activated coconut shell. Journal of Hazardous Materials, v. 161, n. 2-3, p. 1522-1529, 2009.

DUNNE, L. J.; MANOS, G. Adsorption and phase behaviour in nanochannels and nanotubes. New York: Springer, p. 69-89, 2010.

GIRODS, P.; DUFOUR, A.; FERRO, V.; ROGAUME, Y.; ROQAUME, C.; ZOULALIAN A.; CELZARD, A. Activated carbons prepared from wood particleboard wastes: characterization and phenol adsorption capacities. Journal of Hazardous Materials, v. 166, n. 1, p. 491-501, 2009.

GORGULHO, H. F.; MESQUITA, J. P.; GONÇALVES, F.; PEREIRA, M. F. R.; FIGUEIREDO, J. L. Characterization of the surface chemistry of carbon materials by potentiometric titrations and temperature-programmed desorption. Carbon, Elmsford, v. 46, n. 12, p. 1544-1555, 2008.

HAMEED, B. H.; RAHMAN, A. A. Removal of phenol from aqueous solutions by adsorption onto activated carbon prepared from biomass material. Journal of Hazardous Materials, v. 160, n. 2-3, p. 576-581. 2008

IMAZON A atividade madeireira na Amazônia brasileira: produção, receita e mercados. Belém: SFB, 2010. $20 \mathrm{p}$.

KENNEDY, J. F.; PHILLIPS, G. O.; WILLIAMS, P. A. Wood and cellulosics: industrial utilization, biotechnology, structure and properties, ellis horwood. Chichester: E. Horwood. 1987. 1130 p.

KUMAR, K. V.; SIVANESAN, S. Equilibrium data; isotherm parameters and process design for partial and complete isotherm for methylene blue onto activated carbon. Journal of Hazardous Materials, v. 134, p. 237-244, 2006.

MARSH, H.; RODRIGUEZ REINOSO, F. Activated carbon. London: Elsevier; 2006. Disponível em: <http:// aliceweb2.mdic.gov.br//index/home>. Acesso em: 20 jan. 2014. 
Nobre et al. - Produção de carvão ativado de resíduo madeireiro da região Amazônica

MDIC ALICE WEB. Balança comercial para carvões ativados. 2014. Disponível em: < http://aliceweb2. desenvolvimento.gov.br//consulta-ncm/consultar >. Acesso em 20 jan. 2014.

NEVSKAIA, D. M.; SANTIANES, A.; MUÑOZ, V.; GUERRERO-RUIZ, A. Interaction of aqueous solutions of phenol with commercial activated carbons: an adsorption and kinetic study. Carbon, v. 37, n. 7, p. 1065-1074, 1999.

QUANTACHROME AUTOSORB1. Operating Manual: 2006. p. 66-70. 2006.

SANTANA, M. A. E.; OKINO, E. Y. A. Chemical composition of 36 Brazilian Amazon forest wood species. Holzforschung, Berlin, v. 61, p. 469-477, 2007.

SENTHILKUMAAR, S.; KALAAMANI, P.; PORKODI, K.; VARADARAJAN, P.R.; SUBBURAAM, C.V. Adsorption of dissolved reactive red dye from aqueous phase onto activated carbon prepared from agricultural waste. Bioresource Technology, Essex, v. 97, n. 14, 1618-1625, 2006.

SCHETINO JR., M. A.; FREITAS, J. C. C.; CUNHA, A. G.; EMMERICH, F. G.; SOARES, A. B.; SILVA, P. R. N. Preparação e caracterização de carvão ativado quimicamente a partir da casca de arroz. Química Nova, São Paulo, v. 30, n. 7, p. 1663-1668, 2007.

SMALL, C.C. et al. Preparation and characterization of activated carbon from oil sands coke. Fuel, v. 92, p. 69-76, 2012.

STAVROPOULOS, G.G.; ZABANIOTOU, A.A. Production and characterization of activated carbons from olive-seed waste residue. Microporous and Mesoporous Materials, v. 82, n. 1-2, p. 79-85, 2005.

WEBB, P.A.; ORR, C. Analytical methods in fine particle technology. Norcross: Micromeritics Instrument Corporation, p. 53-90. 1997.

XUN, Y. et al. Aqueous dye adsorption on ordered mesoporous carbons. Journal of Colloid and Interface Science, New York, v. 310, n. 1/3, p. 83-89, 2007.

YANG, R. T. Adsorbents: fundamentals and applications. New Jersey: John \& Wiley, 2003. p. 130.

Recebido em 17/07/2014

Aceito para publicação em 12/06/2015 